Tropical Journal of Pharmaceutical Research October 2016; 15 (10): 2197-2207

ISSN: $1596-5996$ (print); 1596-9827 (electronic)

(C) Pharmacotherapy Group, Faculty of Pharmacy, University of Benin, Benin City, 300001 Nigeria.

All rights reserved.

Available online at http://www.tjpr.org

Original Research Article

http://dx.doi.org/10.4314/tjpr.v15i10.19

\title{
Synthesis, characterization, antimicrobial activity and molecular docking studies of combined pyrazol-barbituric acid pharmacophores
}

\author{
Assem Barakat ${ }^{1,2 *}$, Bandar M Al-Qahtani ${ }^{1}$, Abdullah M Al-Majid ${ }^{1}$, M Ali ${ }^{1}$, \\ Mohammed Rafi Shaik ${ }^{1}$, Mohamed HM Al-Agamy ${ }^{3,4}$, Abdul Wadood ${ }^{5}$ \\ ${ }^{1}$ Department of Chemistry, College of Science, King Saud University, PO Box 2455, Riyadh 11451, Saudi Arabia, ${ }^{2}$ Department \\ of Chemistry, Faculty of Science, Alexandria University, P.O. Box 426, Ibrahimia- 21321 Alexandria, ${ }^{3}$ Microbiology and \\ Immunology Department, Faculty of Pharmacy, Al-Azhar University, Cairo, Egypt, ${ }^{4}$ Division of Microbiology, Pharmaceutics \\ Department, College of Pharmacy, King Saud University, PO Box 2457, Riyadh 11451, Saudi Arabia, ${ }^{5}$ Department of \\ Biochemistry, Abdul Wali Khan University, Mardan-23200, Pakistan
}

*For correspondence: Email: ambarakat@ksu.edu.sa; Tel: +966-11-4675884; Fax: +966-11-4675992

\begin{abstract}
Purpose: To synthesize, and determine the antibacterial activity and binding mode of new pyrazolbarbituric acid derivatives in a search for new antimicrobial agents.

Methods: One-pot multi-component reaction of aldehyde derivatives, barbituric acid and 3-methyl-1phenyl-1H-pyrazol-5(4H)-one in the presence of NHEt $t_{2}$ to afford Michael adduct was carried out. The reaction was carried out in water and afforded new heterocycles in a one-step fashion, with expedient work-up and high yield without extraction and purification steps. The synthesized compounds were evaluated for antimicrobial activity using agar disc diffusion. Molecular docking approach via MOE-Dock program was applied to predict the binding interactions of some of the new pyrazol-barbituric acid derivatives against six different target proteins downloaded from Protein Data Bank.

Results: A series of pyrazole-barbituric acid derivatives were successfully synthesized and characterized. The synthesized compounds showed moderate to very good antibacterial activity against S. aureus ATCC 29213 and E. faecalis ATCC29212, as well as also antifungal activity against Candida albicans ATCC 10400

Conclusion: A series of pyrazole-barbituric acid derivatives has been synthesized and some of them display antimicrobial activities.
\end{abstract}

Keywords: Pyrazole, Barbituric acid, Pyrazole-barbituric acid derivatives, Antimicrobial activity, Molecular docking

Tropical Journal of Pharmaceutical Research is indexed by Science Citation Index (SciSearch), Scopus, International Pharmaceutical Abstract, Chemical Abstracts, Embase, Index Copernicus, EBSCO, African Index Medicus, JournalSeek, Journal Citation Reports/Science Edition, Directory of Open Access Journals (DOAJ), African Journal Online, Bioline International, Open-J-Gate and Pharmacy Abstracts

\section{INTRODUCTION}

Multicomponent reactions (MCRs) are one of the most powerful research protocol for generation of complex polyfunctionalized molecules using convergent one-pot transformations [1-7]. In addition, multicomponent reactions in green solvent such as water are of considerable interest. Nitrogen-containing compounds have been known to have a tremendous potential application in chemistry. Besides providing great biological properties, the nitrogen atoms are able to act as donors and find applications in the construction of supramolecular blocks. In this context, Pyrazole derivatives are of particular interest because of their pharmacological profile 
[8-10] such as cyclooxygenase 2 inhibitors (e.g., celecoxib, SC-558, and tepoxalin) (e.g., Fig 1) $[11,12]$ and reduction in obesity for example cannabinoid-1 inverse agonists (e.g., rimonabant) [13].

In particular, fused pyrazoles with other privileged scaffolds possess divergent pharmacological activities [14], they are also useful in the field of luminophores and fluorescence applications [14-20].

Recently, Barakat et al [21-23], synthesized and evaluated some novel zwitterionic adducts derived from pyrimidine-2,4,6-trione which possess anti-oxidant activity. In this context, we have synthesized a new series of pyrazolepyrimidine trione using one pot fashion for the construction of new heterocycles. Their antimicrobial properties and molecular docking were also investigated.

\section{EXPERIMENTAL}

All chemical reagents were purchased from Sigma-Aldrich. IR spectra were measured as CsI pellets on Perkin-Elmer, FT-IR Spectrometer,
Spectrum 1000. NMR spectra were recorded on a Jeol-400 NMR spectrometer. ${ }^{1} \mathrm{H}$-NMR (400 $\mathrm{MHz})$, and ${ }^{13} \mathrm{C}-\mathrm{NMR}(100 \mathrm{MHz})$ were run in either deuterated chloroform $\left(\mathrm{CDCl}_{3}\right)$ or deuterated dimethylsulphoxide (DMSO- $\left.\mathrm{d}_{6}\right)$. Chemical shifts $(\delta)$ are referred in terms of ppm and $\mathrm{J}$-coupling constants are given in $\mathrm{Hz}$. Mass spectra were carried out on a Jeol JMS-600 H equipment. Elemental analysis was carried out on Perkin-Elmer 2400 Elemental Analyzer; CHN mode. All melting points were measured on a Gallenkamp melting point apparatus in open glass capillaries and are uncorrected.

\section{General method for the synthesis of $4 a-0$ (GP1)}

A mixture of aldehyde 1 (1.5 mmol), 1,3dimethylpyrimidine-2,4,6(1H,3H,5H)-trione $\quad 2$, (1.5 mmol), 3-methyl-1-phenyl-1 H-pyrazol-5(4H)one $(1.5 \mathrm{mmol})$ and $\mathrm{Et}_{2} \mathrm{NH}(1.5 \mathrm{mmol}, 155 \mu \mathrm{L})$ in $3 \mathrm{~mL}$ of degassed $\mathrm{H}_{2} \mathrm{O}$ was stirred at room temperature for $1-5 \mathrm{~h}$. The completion of the reaction was monitored by TLC. The solid product was filtered, washed with ether $(3 \times 20$ $\mathrm{mL}$ ), and dried to afford pure product 4a-o.

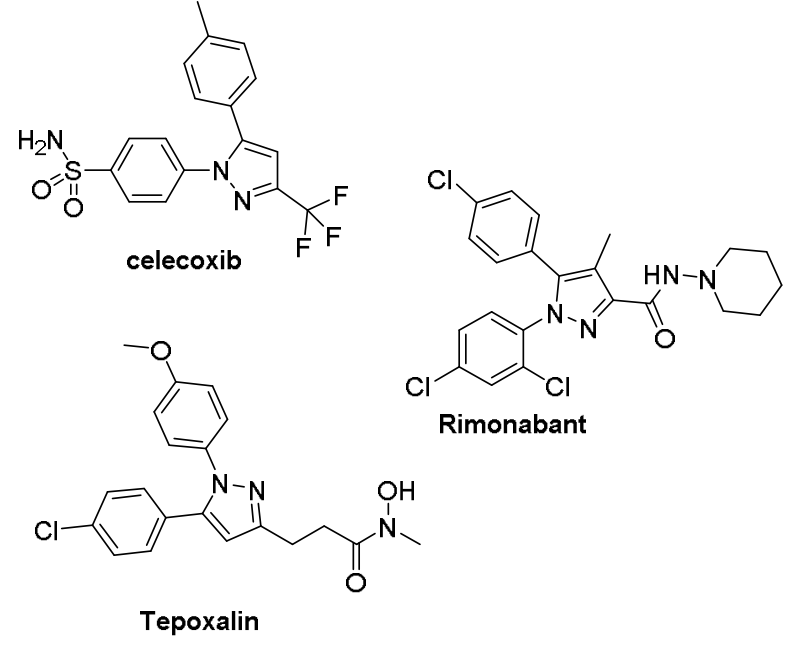

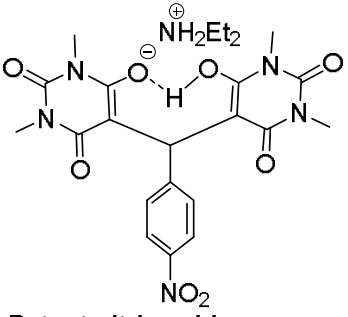

Potent nitric oxide scavenger

$\mathrm{IC}_{50}=69 \pm 1.66 \mu \mathrm{M}$

Std Ascorbic acid $I C_{50}=618 \pm 2.0 \mu \mathrm{M}$

Figure 1: Biologically active pyrazole and barbituric acid scaffolds

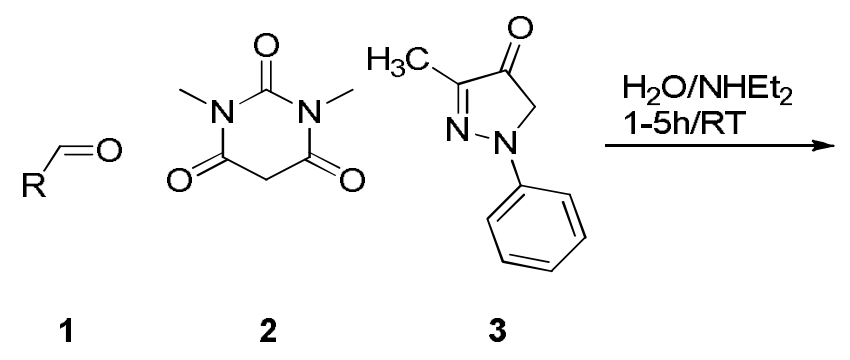<smiles>[R]c1ccccc1C(c1c(O)n(C)c(=O)n(C)c1=O)c1c(O)c(C)nn1-c1ccccc1</smiles>

Scheme-1: Protocol for the synthesis of $4 a-0$ 
Table 1: Different S-substituted alkyl groups for $\mathbf{4 a - 0}$

\begin{tabular}{|c|c|c|c|}
\hline$\#$ & 4 & $\mathbf{R}$ & Yield $(\%)^{b}$ \\
\hline 1 & $4 a$ & $\mathrm{Ph}$ & 96 \\
\hline 2 & 4b & $p-\mathrm{ClPh}$ & 93 \\
\hline 3 & 4c & $p-\mathrm{CH}_{3} \mathrm{Ph}$ & 94 \\
\hline 4 & 4d & $m-\mathrm{CH}_{3} \mathrm{Ph}$ & 93 \\
\hline 5 & $4 e$ & $p-\mathrm{BrPh}$ & 91 \\
\hline 6 & $4 f$ & $m-\mathrm{BrPh}$ & 88 \\
\hline 7 & $4 \mathrm{~g}$ & $p-\mathrm{NO}_{2} \mathrm{Ph}$ & 92 \\
\hline 8 & $4 \mathrm{~h}$ & $m-\mathrm{NO}_{2} \mathrm{Ph}$ & 90 \\
\hline 9 & $4 \mathbf{i}$ & $p-\mathrm{CH}_{3} \mathrm{OPh}$ & 89 \\
\hline 10 & $4 \mathbf{j}$ & $p$-FPh & 92 \\
\hline 11 & 4k & $p-\mathrm{CF}_{3} \mathrm{Ph}$ & 89 \\
\hline 12 & 4I & $2,4-\mathrm{Cl}_{2} \mathrm{Ph}$ & 90 \\
\hline 13 & $4 m$ & $2,6-\mathrm{Cl}_{2} \mathrm{Ph}$ & 87 \\
\hline 14 & $4 n$ & 2-Naphthaldehyde & 89 \\
\hline 15 & 40 & Thiophene & 85 \\
\hline \multicolumn{4}{|c|}{ 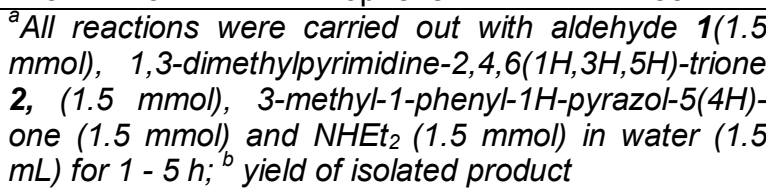 } \\
\hline
\end{tabular}

The different $S$-substituted alkyl groups for $\mathbf{4 a - 0}$ are provided in Table 1

\section{Antimicrobial assay}

The initial screening of antimicrobial activity and minimum inhibitory concentration (MIC) determination for the tested compounds were performed by cup plate method and broth dilution method respectively with different strains (BSAC, 2015). Fifteen synthesized compounds were screened for their antimicrobial activity against six bacterial standard strains; three gram-positive (Staphylococcus aureus ATCC 29213, Enterococcus faecalis ATCC 29212, and Bacillus subtilis ATCC 10400) and three Gram-negative (Escherichia coli ATCC 25922, Proteus vulagris ATCC 6380, and Pseudomonas aeruginosa ATCC 27857) and one unicellular fungi (yeast) standard strain) Candida albicans ATCC 2091). The tested compounds were dissolved in dimethyl sulfoxide (DMSO) to obtain $5120 \mathrm{mg} / \mathrm{mL}$ stock solution.

Three Gram-positive and three Gram-negative bacterial strains and fungi were grown in Cation Adjustment Mueller-Hinton (CAMH) broth (Merck®, Darmstadt, Germany) while C. albicans strain was grown in Sabauraud Dextrose Broth (SDB) to mid-log phase. The suspension was diluted 1:100 in CAMH broth to obtain $1 \times 10^{6}$ $\mathrm{CFU} / \mathrm{mL}$. This suspension was swabbed on a $\mathrm{CAMH}$ agar plate (Merck®, Darmstadt, Germany) and allowed to dry completely. Mueller-Hinton Agar and Sabauraud Dextrose Agar were used for bacteria and fungi respectively. Four wells ( $7 \mathrm{~mm}$ in diameter) were made in agar plate using cork borer. A $1 \mathrm{~mL}$ of stock solution $(5120 \mathrm{mg} / \mathrm{mL})$ was 2 -fold diluted in $1 \mathrm{~mL}$ DMSO to obtain $2560 \mathrm{mg} / \mathrm{mL}$. A $100 \mu \mathrm{L}$ $(256 \mu \mathrm{g})$ of the tested compound was poured in the well using calibrated pipette. The plates were kept in refrigerator at $4{ }^{\circ} \mathrm{C}$ for half an hour to allow diffusion of the compound in the agar. Then, the plates were incubated at $37^{\circ} \mathrm{C}$ for 24 h. After incubation period, the diameter of the inhibition zone was measured and recorded in $\mathrm{mm}$ by aid of ruler. Ciprofloxacin (10 $\mu \mathrm{g} / \mathrm{cup})$ and fluconazole $(10 \mu \mathrm{g} / \mathrm{mL})$ were used as positive controls for antibacterial and antifungal activity, respectively. The experiment was carried out in duplicate and the mean diameter taken [24].

\section{Determination of minimum inhibitory concentration (MIC)}

Minimum inhibitory concentration (MIC) was determined for the compounds that showed antimicrobial activity by cup plate method. Briefly, $2 \mathrm{~mL}$ of CAMH broth (for bacterial strains) and 2 $\mathrm{mL}$ of $\mathrm{SAB}$ (for fungal strain) was dispensed into $7 \mathrm{~mL}$ Peju sterile tubes. For each compound, 14 tubes were used. Tube nos. 13 and 14 were used as positive growth control (no test compound) and negative control for medium sterility (no microorganism), respectively. A $1 \mathrm{~mL}$ aliquot of the stock solution $(5120 \mathrm{mg} / \mathrm{mL})$ was 10-fold diluted in $9 \mathrm{~mL}$ CAMH to obtain 512 $\mathrm{mg} / \mathrm{mL}$. A $2 \mathrm{~mL}$ aliquot of the test compounds $(512 \mathrm{mg} / \mathrm{mL}$ ) was pipetted into the first tube and mixed well. Thereafter, $2 \mathrm{~mL}$ was withdrawn from the 1st tube and added to the 2nd tube to make a two-fold dilution. This procedure was repeated down to the 12th tube a concentration of 0.125 $\mathrm{mg} / \mathrm{mL}$ was obtained. Two millilitres were discarded from the 12th tube. A volume of $2 \mathrm{~mL}$ of inoculum $\left(1 \times 10^{6} \mathrm{CFU} / \mathrm{mL}\right)$ was added to each tube except tube no. 14 to give a final strength of $1 \times 10^{6} \mathrm{CFU} / \mathrm{mL}$. Ciprofloxacin and fluconazole were used as positive control for antibacterial and antifungal assay, respectively. The inoculated tubes were incubated at $37{ }^{\circ} \mathrm{C}$ for 20 h. After the incubation period, the results of MIC were recorded manually and interpreted according to the guidelines of British Society of Antimicrobial Chemotherapy (BSAC)"[24].

\section{Statistical analysis}

All computations were executed in triplicate and statistical analysis was performed with Microsoft Excel 2010. The results are expressed as mean \pm SEM $(n=3)$. Minimum inhibitory concentration (MIC) was computed with suitable dilutions (5120 - $512 \mu \mathrm{g} /$ well) for each sample and results 
calculated using EZ-Fit software (Perrella Scientific Inc, Amherst, USA)" [24].

\section{Molecular modeling and docking data}

Molecular docking simulation is an efficient tool, used to predict binding mode of ligands within target proteins binding pockets. In order to computationally identify anti-fungal and antibacterial (Gram positive) targets for these newly synthesized compounds (4a-4o), six different targets proteins were downloaded from the Protein Data Bank [25], i.e., dihydrofolate reductase (DHFR) (PDB ID 4HOF), secreted aspartic protease (PDB ID 3Q70), and $\mathrm{N}$ myristoyl transferase (PDB ID 1IYL) were chose as anti-fungal targets from Candida albicans, whereas dihydrofolate reductase (PDB ID 3FYV), gyrase $B$ (PDB ID 4URM) and sortase A (PDB ID $2 \mathrm{MLM}$ ) were selected from $S$. aureus as antibacterial targets. On the basis of docking score and interactions of these compounds against all the targets, only two targets, DHFR from C. albicans and gyrase B from S. aureus, were selected as good docking scores and interactions were observed for the synthesized compounds using MOE 2013 [25].

Before docking experiment, two dimensional (2D) structures of all the compounds were modelled on builder implemented in MOE and then their three dimensional (3D) conformation were generated by MOE. The structure of target proteins were prepared, protonated, charged and minimized using MOE. Using the default parameters of docking in MOE, i.e., TMA (Triangle Matcher Algorithm) with London dG and GBVI/WSA dG as rescoring functions were used to develop 30 binding poses for each ligand. All the docking observations along with scoring and different conformations of compounds were stored in the mdb output files.

\section{RESULTS}

The desired zwitterion derivatives 4a-o $[24,25]$ bearing different substituents showed excellent yield (up to $96 \%$ ) as shown in Scheme 1. The preparation of 4a-o was ensued via cascade Aldol-Michael addition of $\mathrm{N}, \mathrm{N}$-dimethyl barbituric acid, 3-methyl-1-phenyl-1 H-pyrazol-5(4H)-one and aldehyde mediated by aquoues $\mathrm{NHEt}_{2}$. Notably, a variety of functional groups such as hydroxyl, methoxy and chloro were tolerated under our new reaction protocol. The chemical structures of all the synthesized compounds were deduced with the aid of physical and spectroscopic methods.
5-((6-Hydroxy-1,3-dimethyl-2,4-dioxo-1,2,3,4tetrahydropyrimidin-5-yl)(phenyl)methyl)-3methyl-1-phenyl-1H-pyrazol-4-olate (4a)

4a was prepared according to (GP1) from benzaldehyde yielding orange materials (yield 96\%). m.p: $116{ }^{\circ} \mathrm{C}$; IR (Csl, $\mathrm{cm}^{-1}$ ): 3449, 3060, 2988, 1661, 1581, 1501, 1426, 1367; ${ }^{1} \mathrm{H}-\mathrm{NMR}$ $\left(400 \mathrm{MHz}, \mathrm{DMSO}-d_{6}\right): \delta 14.48(\mathrm{~s}, 1 \mathrm{H}, \mathrm{OH}), 7.33-$ $7.09(\mathrm{~m}, 10 \mathrm{H}, \mathrm{Ph}), 5.52(\mathrm{~s}, 1 \mathrm{H}$, benzyl-H), 3.36 $\left(\mathrm{m}, 6 \mathrm{H}, \mathrm{CH}_{3}\right), 2.88\left(\mathrm{q}, 4 \mathrm{H}, J=7.3 \mathrm{~Hz}, \mathrm{CH}_{2} \mathrm{CH}_{3}\right)$, $2.19\left(\mathrm{~s}, 3 \mathrm{H}, \mathrm{CH}_{3}\right), \quad 1.13(\mathrm{t}, 6 \mathrm{H}, J=7.3 \mathrm{~Hz}$, $\left.\mathrm{CH}_{2} \mathrm{CH}_{3}\right) ;{ }^{13} \mathrm{C}-\mathrm{NMR}\left(100 \mathrm{MHz}\right.$, DMSO- $\left.d_{6}\right): \delta=$ 198.0, 174.8, 164.0, 163.6, 163.2, 151.4, 146.9, $138.0,128.8,127.9,127.5,126.9,125.9,121.9$, 121.8, 91.2, 65.8, 42.1, 12.6, 12.2, 10.7; Anal. for $\mathrm{C}_{27} \mathrm{H}_{33} \mathrm{~N}_{5} \mathrm{O}_{4}$; calcd $\mathrm{C}, 65.97 ; \mathrm{H}, 6.77 ; \mathrm{N}$, 14.25;Found: C, 65.98; H, 6.76; N, 14.24; LC/MS (ESI): $492[\mathrm{M}]^{+}$.

\section{5-((4-Chlorophenyl)(6-hydroxy-1,3-dimethyl- 2,4-dioxo-1,2,3,4-tetrahydropyrimidin-5- yl)methyl)-3-methyl-1-phenyl-1H-pyrazol-4- olate $(4 b)$}

4b was prepared according to (GP1) from $p$ cholorbenzaldehyde yielding rose materials (yield 93\%). m.p: $162{ }^{\circ} \mathrm{C}$; IR (Csl, $\mathrm{cm}^{-1}$ ): 3444, 3045, 2987, 2721, 2495, 1679, 1579, 1502, 1487, 1370; ${ }^{1} \mathrm{H}-\mathrm{NMR}\left(400 \mathrm{MHz}, \mathrm{CDCl}_{3}\right): \delta 17.62(\mathrm{~s}, 1 \mathrm{H}$, $\mathrm{OH}$ ), 8.45 (bs, NH, NHEt $\left.{ }_{2}\right), 7.25-7.13(\mathrm{~m}, 10 \mathrm{H}$, $\mathrm{Ph}), \quad 5.46(\mathrm{~s}, 1 \mathrm{H}$, benzyl-H), $3.17(\mathrm{~m}, 6 \mathrm{H}$, $\mathrm{CH}_{2} \mathrm{CH}_{3}$ ), 2.48(q, $\left.4 \mathrm{H}, J=7.3 \mathrm{~Hz}, \mathrm{CH}_{2} \mathrm{CH}_{3}\right), 2.16$ $\left(\mathrm{s}, 3 \mathrm{H}, \mathrm{CH}_{3}\right), \quad 1.03\left(\mathrm{t}, 6 \mathrm{H}, J=7.3 \mathrm{~Hz}, \mathrm{CH}_{2} \mathrm{CH}_{3}\right)$; ${ }^{13} \mathrm{C}-\mathrm{NMR}\left(100 \mathrm{MHz}, \mathrm{CDCl}_{3}\right): \delta=198.2,174.8$, 164.0, 163.6, 163.2, 151.4, 139.7, 139.1, 131.4, 128.3, 127.8, 96.8, 91.2, 44.1, 42.1, 34.2, 28.6, 12.4, 12.3, 11.3; Anal. for $\mathrm{C}_{27} \mathrm{H}_{32} \mathrm{ClN}_{5} \mathrm{O}_{4}$; calcd $\mathrm{C}$, 61.65; $\mathrm{H}, 6.13 ; \mathrm{Cl}, 6.74 ; \mathrm{N}, 13.31$; Found: $\mathrm{C}$, 61.66; H, 6.14; Cl, 6.75; N, 13.29; LC/MS (ESI): $527[\mathrm{M}]^{+}$.

5-((6-Hydroxy-1,3-dimethyl-2,4-dioxo-1,2,3,4tetrahydropyrimidin-5-yl)(p-tolyl)methyl)-3methyl-1-phenyl-1H-pyrazol-4-olate (4c)

4c was prepared according to (GP1) from $p$ toulaldehyde yielding orange materials (yield 94\%). m.p: $147{ }^{\circ} \mathrm{C}$; IR (CsI, $\mathrm{cm}^{-1}$ ): 3432, 2983, 2716, 2490, 1683, 1578, 1501, 1362; ${ }^{1} \mathrm{H}-\mathrm{NMR}$ $\left(400 \mathrm{MHz}, \mathrm{DMSO}-d_{6}\right): \delta 14.31(\mathrm{~s}, 1 \mathrm{H}, \mathrm{OH}), 9.94$ (bs, NH, NHEt 2 ), 7.35-7.00 (m, 9H, Ph), 5.27 (s, $1 \mathrm{H}$, benzyl-H), 3.30(t, $6 \mathrm{H}, J=7.3 \mathrm{~Hz}, \mathrm{CH}_{2} \mathrm{CH}_{3}$ ), $2.42\left(\mathrm{~s}, 3 \mathrm{H}, \mathrm{CH}_{3}\right), 2.24\left(\mathrm{~s}, 3 \mathrm{H}, \mathrm{CH}_{3}\right), 2.16(\mathrm{~s}, 3 \mathrm{H}$, $\left.\mathrm{CH}_{3}\right), 0.86$ (t, $\left.6 \mathrm{H}, J=7.3 \mathrm{~Hz}, \mathrm{CH}_{2} \mathrm{CH}_{3}\right) ;{ }^{13} \mathrm{C}-\mathrm{NMR}$ $\left(100 \mathrm{MHz}, \mathrm{CDCl}_{3}\right): \delta=192.5,163.1,157.4$, 152.4, 152.2, 147.4, 146.0, 144.6, 139.8, 139.7, $130.4,129.4,128.8,128.6,119.9,119.6,102.5$, 91.5, 41.2, 31.2, 12.8, 11.1Anal. for $\mathrm{C}_{28} \mathrm{H}_{35} \mathrm{~N}_{5} \mathrm{O}_{4}$; calcd C, 66.51; H, 6.98; N, 13.85; Found: C, 
66.52; H, 6.99; N, 13.83; ; LC/MS (ESI): 506 $[\mathrm{M}]^{+}$.

\section{5-((6-Hydroxy-1,3-dimethyl-2,4-dioxo-1,2,3,4- tetrahydropyrimidin-5-yl)(m-tolyl)methyl)-3- methyl-1-phenyl-1H-pyrazol-4-olate (4d)}

4d was prepared according to (GP1) from $m$ toulaldehyde yielding red materials (yield 93\%). m.p: $98{ }^{\circ} \mathrm{C}$; IR (Csl, $\mathrm{cm}^{-1}$ ): 3449, 3043, 2987, 2734, 2509, 1681, 1581, 1501, 1426, 1369; ${ }^{1} \mathrm{H}-$ NMR $\left(400 \mathrm{MHz}, \mathrm{DMSO}-d_{6}\right): \delta 17.40(\mathrm{~s}, 1 \mathrm{H}, \mathrm{OH})$, 9.97 (bs, NH, NHEt 2 ), 7.65-7.07 (m, 9H, Ph), $5.45(\mathrm{~s}, 1 \mathrm{H}$, benzyl-H), 2.42(t, $4 \mathrm{H}, J=7.3 \mathrm{~Hz}$, $\left.\mathrm{CH}_{2} \mathrm{CH}_{3}\right), 2.34\left(\mathrm{~s}, 3 \mathrm{H}, \mathrm{CH}_{3}\right), 2.24\left(\mathrm{~s}, 3 \mathrm{H}, \mathrm{CH}_{3}\right)$, $2.22\left(\mathrm{~s}, 3 \mathrm{H}, \mathrm{CH}_{3}\right), \quad 0.83(\mathrm{t}, 6 \mathrm{H}, \quad J=7.3 \mathrm{~Hz}$, $\left.\mathrm{CH}_{2} \mathrm{CH}_{3}\right) ;{ }^{13} \mathrm{C}-\mathrm{NMR}\left(100 \mathrm{MHz}, \mathrm{DMSO}-d_{6}\right): \delta=$ $192.5,163.1,157.4,152.4,152.2,147.4,146.0$, $144.6,139.8,139.7,130.4,129.4,128.8,128.6$, $119.9,119.6,102.5,91.5,41.4,21.5,12.8$, 11.1Anal. for $\mathrm{C}_{28} \mathrm{H}_{35} \mathrm{~N}_{5} \mathrm{O}_{4}$; calcd $\mathrm{C}, 66.51 ; \mathrm{H}$, 6.98; N, 13.85; Found: C, 66.53; H, 6.98; N, 13.85; LC/MS (ESI): 506 [M] ${ }^{+}$.

\section{5-((4-Bromophenyl)(6-hydroxy-1,3-dimethyl- 2,4-dioxo-1,2,3,4-tetrahydropyrimidin-5- yl)methyl)-3-methyl-1-phenyl-1H-pyrazol-4- olate $(4 e)$}

4e was prepared according to (GP1) from $p$ bromobenzaldehyde yielding orange materials (yield 91\%). m.p: $104{ }^{\circ} \mathrm{C}$; IR (Csl, $\mathrm{cm}^{-1}$ ): 3451 , 2988, 2737, 2508, 1677, 1581, 1502, 1429, 1371; ${ }^{1} \mathrm{H}-\mathrm{NMR}\left(400 \mathrm{MHz}\right.$, DMSO- $\left.d_{6}\right): \delta 14.33(\mathrm{~s}$, $1 \mathrm{H}, \mathrm{OH}$ ), 9.96 (bs, NH, NHEt $\left.{ }_{2}\right), 7.82(\mathrm{~d}, 2 \mathrm{H}, J=$ 7.3Hz, Ph), 7.35-7.07 (m, 7H, Ph), $5.46(\mathrm{~s}, 1 \mathrm{H}$, benzyl-H), 2.89(t, $\left.4 \mathrm{H}, J=7.3 \mathrm{~Hz}, \mathrm{CH}_{2} \mathrm{CH}_{3}\right), 3.51$ $\left(\mathrm{s}, 6 \mathrm{H}, \mathrm{CH}_{3}\right), 2.18\left(\mathrm{~s}, 3 \mathrm{H}, \mathrm{CH}_{3}\right), 1.12(\mathrm{t}, 6 \mathrm{H}, J=$ 7.3Hz, $\left.\mathrm{CH}_{2} \mathrm{CH}_{3}\right) ;{ }^{13} \mathrm{C}-\mathrm{NMR}\left(100 \mathrm{MHz}\right.$, DMSO- $d_{6}$ ): $\delta=192.5,163.1,157.4,152.4,152.2,147.4$, $146.0,144.6,139.8,139.7,130.4,129.4,128.8$, $128.6,119.9,119.6,102.5,91.5,41.2,31.2$, 12.8, 11.1; Anal. for $\mathrm{C}_{27} \mathrm{H}_{32} \mathrm{BrN}_{5} \mathrm{O}_{4}$; calcd $\mathrm{C}$, 56.85; H, 5.65; Br, 14.01; N, 12.28; Found: C, 56.85; H, 5.64; Br, 14.05; N, 12.29; LC/MS (ESI): $571[\mathrm{M}]^{+}$.

\section{5-((3-Bromophenyl)(6-hydroxy-1,3-dimethyl- 2,4-dioxo-1,2,3,4-tetrahydropyrimidin-5- yl)methyl)-3-methyl-1-phenyl-1H-pyrazol-4- olate $(\mathbf{4 f})$}

4f was prepared according to (GP1) from $\mathrm{m}$ bromobenzaldehyde yielding orange materials (yield 88\%). m.p: $163^{\circ} \mathrm{C}$; IR (Csl, $\mathrm{cm}^{-1}$ ): 3452 , 2989, 2736, 2510, 1678, 1584, 1502, 1429, $1371 ;{ }^{1} \mathrm{H}-\mathrm{NMR}\left(400 \mathrm{MHz}, \mathrm{DMSO}-d_{6}\right): \delta 14.36(\mathrm{~s}$, $1 \mathrm{H}, \mathrm{OH}), 9.95$ (bs, NH, NHEt $\left.{ }_{2}\right), 7.89(\mathrm{~d}, 1 \mathrm{H}, J=$
7.3Hz, Ph), 7.31-7.12 (m, 8H, Ph), $5.51(\mathrm{~s}, 1 \mathrm{H}$, benzyl-H), 2.87(t, $\left.4 \mathrm{H}, J=7.3 \mathrm{~Hz}, \mathrm{CH}_{2} \mathrm{CH}_{3}\right), 3.50$ $\left(\mathrm{s}, 6 \mathrm{H}, \mathrm{CH}_{3}\right), 2.15\left(\mathrm{~s}, 3 \mathrm{H}, \mathrm{CH}_{3}\right), 1.12(\mathrm{t}, 6 \mathrm{H}, J=$ 7.3 $\left.\mathrm{Hz}, \mathrm{CH}_{2} \mathrm{CH}_{3}\right) ;{ }^{13} \mathrm{C}-\mathrm{NMR}\left(100 \mathrm{MHz}\right.$, DMSO-d $\left.d_{6}\right)$ : $\delta=192.5,163.1,157.3,152.4,152.1,148.3$, $147.4,146.0,140.4,139.7,130.0,129.4,128.8$, $128.6,123.4,119.9,119.6,102.5,91.5,41.2$, 31.2, 12.9, 11.1; Anal. for $\mathrm{C}_{27} \mathrm{H}_{32} \mathrm{BrN}_{5} \mathrm{O}_{4}$; calcd C, 56.85; H, 5.65; Br, 14.01; N, 12.28; Found: C, 56.83; H, 5.64; Br, 14.04; N, 12.30; LC/MS (ESI): $571[\mathrm{M}]^{+}$.

5-((6-Hydroxy-1,3-dimethyl-2,4-dioxo-1,2,3,4tetrahydropyrimidin-5-yl)(4-

nitrophenyl)methyl)-3-methyl-1-phenyl-1Hpyrazol-4-olate $(\mathbf{4 g})$

$\mathbf{4 g}$ was prepared according to (GP1) from $p$ nitrobenzaldehyde yielding paige materials (yield 92\%). m.p: $195{ }^{\circ} \mathrm{C}$; IR (Csl, $\mathrm{cm}^{-1}$ ): 3453, 3062, 2989, 2507, 1678, 1585, 1513, 1454, 1346; ${ }^{1} \mathrm{H}-$ NMR (400 MHz, DMSO- $\left.d_{6}\right): \delta 17.53(\mathrm{~s}, 1 \mathrm{H}, \mathrm{OH})$, 10.15 (bs, NH, NHEt $), 8.03(\mathrm{~d}, 2 \mathrm{H}, J=7.3 \mathrm{~Hz}$, $\mathrm{Ph}), 7.57(\mathrm{~d}, 2 \mathrm{H}, J=7.3 \mathrm{~Hz}, \mathrm{Ph}), 7.57-7.25(\mathrm{~m}$, $5 \mathrm{H}, \mathrm{Ph}), 5.57(\mathrm{~s}, 1 \mathrm{H}$, benzyl-H), $3.33(\mathrm{~s}, 6 \mathrm{H}$, $\left.\mathrm{CH}_{3}\right), \quad 3.32\left(\mathrm{t}, 4 \mathrm{H}, J=7.3 \mathrm{~Hz}, \mathrm{CH}_{2} \mathrm{CH}_{3}\right), 2.08(\mathrm{~s}$, $\left.3 \mathrm{H}, \mathrm{CH}_{3}\right), 0.96\left(\mathrm{t}, 6 \mathrm{H}, J=7.3 \mathrm{~Hz}, \mathrm{CH}_{2} \mathrm{CH}_{3}\right) ;{ }^{13} \mathrm{C}-$ NMR $\left(100 \mathrm{MHz}\right.$, DMSO- $\left.d_{6}\right): \delta 192.7,163.1$, 157.3, 152.4, 152.1, 148.3, 147.4, 146.0, 140.4, $139.7,130.0,129.4,129.0,128.6,123.4,119.9$, 119.6, 102.5, 91.5, 42.0, 28.5, 12.9, 11.1; Anal. for $\mathrm{C}_{27} \mathrm{H}_{32} \mathrm{~N}_{6} \mathrm{O}_{6}$; calcd $\mathrm{C}, 60.44 ; \mathrm{H}, 6.01 ; \mathrm{N}$, 15.66; Found: C, 60.44; H, 6.02; N, 15.67; LC/MS (ESI): 537 [M] ${ }^{+}$.

5-((6-Hydroxy-1,3-dimethyl-2,4-dioxo-1,2,3,4tetrahydropyrimidin-5-yl)(3-

nitrophenyl)methyl)-3-methyl-1-phenyl-1Hpyrazol-4-olate $(4 \mathrm{~h})$

4h was prepared according to (GP1) from $\mathrm{m}$ nitrobenzaldehyde yielding orange materials (yield 90\%). m.p: $116{ }^{\circ} \mathrm{C}$; IR (Csl, $\mathrm{cm}^{-1}$ ): 3451 , 2990, 2508, 1677, 1583, 1526, 1348; ${ }^{1} \mathrm{H}-\mathrm{NMR}$ $\left(400 \mathrm{MHz}, \mathrm{DMSO}-d_{6}\right): \delta 14.10(\mathrm{~s}, 1 \mathrm{H}, \mathrm{OH})$, 10.11(bs, NH, NHEt $\left.{ }_{2}\right), 7.60(\mathrm{~d}, 1 \mathrm{H}, J=7.3 \mathrm{~Hz}$, $\mathrm{Ph}), 7.60-7.15(\mathrm{~m}, 8 \mathrm{H}, \mathrm{Ph}), 5.59(\mathrm{~s}, 1 \mathrm{H}$, benzyl$\mathrm{H}), 3.33\left(\mathrm{~s}, 6 \mathrm{H}, \mathrm{CH}_{3}\right), \quad 2.50(\mathrm{t}, 4 \mathrm{H}, J=7.3 \mathrm{~Hz}$, $\left.\mathrm{CH}_{2} \mathrm{CH}_{3}\right), 2.23\left(\mathrm{~s}, 3 \mathrm{H}, \mathrm{CH}_{3}\right), 1.00$ (t, $6 \mathrm{H}, J=$ 7.3Hz, $\left.\mathrm{CH}_{2} \mathrm{CH}_{3}\right){ }^{13} \mathrm{C}-\mathrm{NMR}\left(100 \mathrm{MHz}\right.$, DMSO- $\left.d_{6}\right)$ : $\delta 192.5,163.1,156.3,152.4,152.1,148.3$, $146.9,138.9,129.4,128.8,128.6,125.9,122.5$, $122.3,122.1,121.1,102.5,91.5,42.0,34.3$, 28.7, 12.7, 11.3; Anal. for $\mathrm{C}_{27} \mathrm{H}_{32} \mathrm{~N}_{6} \mathrm{O}_{6}$; calcd $\mathrm{C}$, $60.44 ; \mathrm{H}, 6.01 ; \mathrm{N}, 15.66$; Found: $\mathrm{C}, 60.45 ; \mathrm{H}$, 6.02; N, 15.65; LC/MS (ESI): $537[\mathrm{M}]^{+}$.

Trop J Pharm Res, October 2016; 15(10): 2201 
5-((6-Hydroxy-1,3-dimethyl-2,4-dioxo-1,2,3,4tetrahydropyrimidin-5-yl)(4methoxyphenyl)methyl)-3-methyl-1-phenyl1H-pyrazol-4-olate (4i)

4i was prepared according to (GP1) from anisaldehyde yielding orange materials (yield 89\%). m.p: $105{ }^{\circ} \mathrm{C}$; IR (Csl, $\mathrm{cm}^{-1}$ ): 3455, 2998, 273, 2502, 1681, 1584, 1556, 1499, 1430, 1361, 1268; ${ }^{1} \mathrm{H}-\mathrm{NMR}\left(400 \mathrm{MHz}\right.$, DMSO- $\left.d_{6}\right): \delta 14.50(\mathrm{~s}$, $1 \mathrm{H}, \mathrm{OH}$ ), 8.68 (bs, NH, NHEt $\left.{ }_{2}\right), 7.76(\mathrm{~d}, 2 \mathrm{H}, J=$ $7.3 \mathrm{~Hz}, \mathrm{Ph}), 7.41(\mathrm{~d}, 2 \mathrm{H}, J=7.3 \mathrm{~Hz}, \mathrm{Ph}), 7.19-$ $7.08(\mathrm{~m}, 5 \mathrm{H}, \mathrm{Ph}), 5.51(\mathrm{~s}, 1 \mathrm{H}$, benzyl-H), $3.85(\mathrm{~s}$, $\left.6 \mathrm{H}, \mathrm{CH}_{3}\right), 2.28\left(\mathrm{~s}, 3 \mathrm{H}, \mathrm{CH}_{3}\right), 3.44(\mathrm{t}, 4 \mathrm{H}, J=$ 7.3Hz, $\left.\mathrm{CH}_{2} \mathrm{CH}_{3}\right), 2.28\left(\mathrm{~s}, 3 \mathrm{H}, \mathrm{CH}_{3}\right), 1.06(\mathrm{t}, 6 \mathrm{H}, J$ $\left.=7.3 \mathrm{~Hz}, \mathrm{CH}_{2} \mathrm{CH}_{3}\right) ;{ }^{13} \mathrm{C}-\mathrm{NMR}(100 \mathrm{MHz}$, DMSO$\left.d_{6}\right): \delta=192.5,163.5,161.8,157.4,151.7,147.9$, $146.1,138.4,136.8,136.8,128.8,128.7,126.2$, $120.2,118.3,114.3,113.4,104.6,91.5,55.6$, $41.9,31.2,18.5,15.1,13.1,11.8$; Anal. for $\mathrm{C}_{28} \mathrm{H}_{35} \mathrm{~N}_{5} \mathrm{O}_{5}$; calcd C, 64.47; $\mathrm{H}, 6.76 ; \mathrm{N}, 13.43$; Found: C, 64.47; H, 6.76; N, 13.43; LC/MS (ESI): $552[\mathrm{M}]^{+}$.

\section{5-((4-Fluorophenyl)(6-hydroxy-1,3-dimethyl- 2,4-dioxo-1,2,3,4-tetrahydropyrimidin-5- yl)methyl)-3-methyl-1-phenyl-1H-pyrazol-4- olate $(4 \mathrm{j})$}

4j was prepared according to the general procedure (GP1) from $p$-flurobenzaldehyde yielding orange materials (yield 92\%). m.p: 108 ${ }^{\circ} \mathrm{C}$; IR (Csl, $\left.\mathrm{cm}^{-1}\right)$ : 3452, 3064, 2991, 2739, 2511, 16800, 1582, 1503, 1455, 1370; ${ }^{1} \mathrm{H}-\mathrm{NMR}$ $\left(400 \mathrm{MHz}, \mathrm{DMSO}-d_{6}\right): \delta 14.40(\mathrm{~s}, 1 \mathrm{H}, \mathrm{OH}), 9.95$ (bs, $\left.\mathrm{NH}, \mathrm{NHEt}_{2}\right), 7.86(\mathrm{~d}, 2 \mathrm{H}, J=7.3 \mathrm{~Hz}, \mathrm{Ph})$, $7.36(\mathrm{~d}, 2 \mathrm{H}, J=7.3 \mathrm{~Hz}, \mathrm{Ph}), 7.36-6.96(\mathrm{~m}, 5 \mathrm{H}$, $\mathrm{Ph}), 5.49\left(\mathrm{~s}, 1 \mathrm{H}\right.$, benzyl-H), $3.50\left(\mathrm{~s}, 6 \mathrm{H}, \mathrm{CH}_{3}\right)$, $2.87\left(\mathrm{t}, 4 \mathrm{H}, \mathrm{J}=7.3 \mathrm{~Hz}, \mathrm{CH}_{2} \mathrm{CH}_{3}\right), 2.17\left(\mathrm{~s}, 3 \mathrm{H}, \mathrm{CH}_{3}\right)$, $1.12\left(\mathrm{t}, 6 \mathrm{H}, \mathrm{J}=7.3 \mathrm{~Hz}, \mathrm{CH}_{2} \mathrm{CH}_{3}\right) ;{ }^{13} \mathrm{C}-\mathrm{NMR}(100$ $\left.\mathrm{MHz}, \mathrm{DMSO}-d_{6}\right): \delta=191.8,163.5,161.8,157.3$, $152.4,152.2,147.4,146.0,140.1,139.7,128.7$, $128.6,128.5,123.7,119.9,119.5,102.9,91.7$, $41.9, \quad 31.5, \quad 28.5,12.8,11.11$; Anal. for $\mathrm{C}_{27} \mathrm{H}_{32} \mathrm{FN}_{5} \mathrm{O}_{4}$; calcd C, 63.64; $\mathrm{H}, 6.33 ; \mathrm{F}, 3.73 ; \mathrm{N}$, 13.74; Found: C, 63.65; H, 6.35; F, 3.70; N, 13.75; LC/MS (ESI): 510 [M] ${ }^{+}$.

\section{5-((6-Hydroxy-1,3-dimethyl-2,4-dioxo-1,2,3,4- tetrahydropyrimidin-5-yl)(4- \\ (trifluoromethyl)phenyl)methyl)-3-methyl-1- phenyl-1H-pyrazol-4-olate (4k)}

4k was prepared according to (GP1) from $p$ trifluromethylbenzaldehyde yielding orange materials (yield 89\%). m.p: $171^{\circ} \mathrm{C}$; IR (Csl, $\mathrm{cm}^{-}$ $\left.{ }^{1}\right)$ : 3452, 3063, 2992, 2510, 1664, 1582, 1502, 1430, 1326; ${ }^{1} \mathrm{H}-\mathrm{NMR}\left(400 \mathrm{MHz}, \mathrm{DMSO}-d_{6}\right): \delta$ 17.40 (s, 1H, OH), 10.09(bs, NH, NHEt 2 ), 7.54 $(\mathrm{d}, 1 \mathrm{H}, J=7.3 \mathrm{~Hz}, \mathrm{Ph}), 7.42-7.25(\mathrm{~m}, 8 \mathrm{H}, \mathrm{Ph})$, $5.57\left(\mathrm{~s}, 1 \mathrm{H}\right.$, benzyl-H), $3.31\left(\mathrm{~s}, 6 \mathrm{H}, \mathrm{CH}_{3}\right), 2.89(\mathrm{t}$, $\left.4 \mathrm{H}, J=7.3 \mathrm{~Hz}, \mathrm{CH}_{2} \mathrm{CH}_{3}\right), 2.29\left(\mathrm{~s}, 3 \mathrm{H}, \mathrm{CH}_{3}\right), 0.88$ $\left(\mathrm{t}, 6 \mathrm{H}, J=7.3 \mathrm{~Hz}, \mathrm{CH}_{2} \mathrm{CH}_{3}\right) ;{ }^{13} \mathrm{C}-\mathrm{NMR}(100 \mathrm{MHz}$, DMSO- $d_{6}$ ): $\delta 192.5,163.1,156.3,152.4,152.1$, $148.3,146.9,138.7,128.8,128.7,128.0,127.3$, $125.8,124.8,122.1,119.5,102.5,91.5,41.5$, 34.3, 28.2, 12.6, 11.0; Anal. for $\mathrm{C}_{28} \mathrm{H}_{32} \mathrm{~F}_{3} \mathrm{~N}_{5} \mathrm{O}_{4}$; calcd C, 60.10; H, 5.76; F, 10.19; N, 12.52; Found: C, 60.11; H, 5.75; F, 10.21; N, 12.54; LC/MS (ESI): $560[\mathrm{M}]^{+}$.

\section{5-((2,4-Dichlorophenyl)(6-hydroxy-1,3-} dimethyl-2,4-dioxo-1,2,3,4tetrahydropyrimidin-5-yl)methyl)-3-methyl-1phenyl-1H-pyrazol-4-olate (4I)

4I was prepared according to (GP1) from 2,4dicholrobenzaldehyde yielding orange materials (yield 90\%). m.p: $109{ }^{\circ} \mathrm{C}$; IR (Csl, $\mathrm{cm}^{-1}$ ): 3450, 3064, 2989, 2735, 2509, 1680, 1583, 1501, 1456, 1376; ${ }^{1} \mathrm{H}-\mathrm{NMR}\left(400 \mathrm{MHz}, \mathrm{DMSO}-d_{6}\right): \delta$ 14.30 (s, 1H, OH), 10.40(bs, NH, NHEt $\left.{ }_{2}\right), 7.53$ $(\mathrm{d}, 1 \mathrm{H}, J=7.3 \mathrm{~Hz}, \mathrm{Ph}), 7.27-7.09(\mathrm{~m}, 7 \mathrm{H}, \mathrm{Ph})$, $5.48\left(\mathrm{~s}, 1 \mathrm{H}\right.$, benzyl-H), $3.31\left(\mathrm{~s}, 3 \mathrm{H}, \mathrm{CH}_{3}\right), 3.18$ $\left(\mathrm{s}, 3 \mathrm{H}, \mathrm{CH}_{3}\right), \quad 2.36\left(\mathrm{t}, 4 \mathrm{H}, J=7.3 \mathrm{~Hz}, \mathrm{CH}_{2} \mathrm{CH}_{3}\right)$, $2.27\left(\mathrm{~s}, 3 \mathrm{H}, \quad \mathrm{CH}_{3}\right), \quad 0.89$ (t, $6 \mathrm{H}, \quad J=7.3 \mathrm{~Hz}$, $\left.\mathrm{CH}_{2} \mathrm{CH}_{3}\right) ;{ }^{13} \mathrm{C}-\mathrm{NMR} \quad\left(100 \mathrm{MHz}\right.$, DMSO- $\left.d_{6}\right): \delta$ $188.7,163.1,156.9,146.9,138.5,133.7,132.2$, $131.7,129.1,129.0,128.9,128.8,126.6,125.8$, 122.2, 119.1, 102.7, 91.4, 41.2, 32.4, 28.22, 12.7, 11.0, 10.9; Anal. for $\mathrm{C}_{27} \mathrm{H}_{31} \mathrm{C}_{12} \mathrm{~N}_{5} \mathrm{O}_{4}$; calcd C, 57.86; H, 5.57; Cl, 12.65; N, 12.50; Found: C, 57.85; H, 5.57; Cl, 12.62; N, 12.53; LC/MS (ESI): $561[\mathrm{M}]^{+}$.

\section{5-((2,6-Dichlorophenyl)(6-hydroxy-1,3- dimethyl-2,4-dioxo-1,2,3,4- tetrahydropyrimidin-5-yl)methyl)-3-methyl-1- phenyl-1H-pyrazol-4-olate (4m)}

4m was prepared according to (GP1) from 2,6dicholrobenzaldehyde yielding yellow materials (yield 97\%). m.p: $88{ }^{\circ} \mathrm{C}$; IR (Csl, $\mathrm{cm}^{-1}$ ): 3449 , 2988, 2787, 2507, 1677, 1582, 1499, 1431, 1370; ${ }^{1} \mathrm{H}-\mathrm{NMR}\left(400 \mathrm{MHz}, \mathrm{DMSO}-d_{6}\right): \delta 14.30(\mathrm{~s}$, $1 \mathrm{H}, \mathrm{OH}$ ), 10.40(bs, NH, NHEt $\left.{ }_{2}\right), 7.53(\mathrm{~d}, 1 \mathrm{H}, J=$ 7.3Hz, Ph), 7.36-7.21 (m, 7H, Ph), $5.77(\mathrm{~s}, 1 \mathrm{H}$, benzyl-H), $3.07\left(\mathrm{~s}, 6 \mathrm{H}, \mathrm{CH}_{3}\right), \quad 2.87(\mathrm{t}, 4 \mathrm{H}, J=$ 7.3Hz, $\left.\mathrm{CH}_{2} \mathrm{CH}_{3}\right), 1.96\left(\mathrm{~s}, 3 \mathrm{H}, \mathrm{CH}_{3}\right), 1.13(\mathrm{t}, 6 \mathrm{H}, J$ $\left.=7.3 \mathrm{~Hz}, \mathrm{CH}_{2} \mathrm{CH}_{3}\right){ }^{13} \mathrm{C}-\mathrm{NMR}(100 \mathrm{MHz}$, DMSO$\left.d_{6}\right): \delta 188.7,163.1,156.9,146.9,138.5,133.7$, $132.2,131.7,129.1,129.0,128.9,128.8,126.6$, $125.8,122.2,119.1,102.7,91.4,41.2,32.4$, 28.22, 12.7, 11.0, 10.9; Anal. for $\mathrm{C}_{27} \mathrm{H}_{31} \mathrm{C}_{12} \mathrm{~N}_{5} \mathrm{O}_{4}$; calcd C, 57.86; H, 5.57; Cl, 12.65; N, 12.50; Found: $\mathrm{C}, 57.87$; $\mathrm{H}, 5.58 ; \mathrm{Cl}, 12.63 ; \mathrm{N}, 12.52$; LC/MS (ESI): 561[M] $]^{+}$. 
5-((6-Hydroxy-1,3-dimethyl-2,4-dioxo-1,2,3,4tetrahydropyrimidin-5-yl)(naphthalen-2yl)methyl)-3-methyl-1-phenyl-1H-pyrazol-4olate $(4 n)$

4n was prepared according to (GP1) from naphthaldehyde yielding orange materials (yield 89\%). m.p: $94{ }^{\circ} \mathrm{C}$; IR (Csl, $\mathrm{cm}^{-1}$ ): 3448, 3054, 2988, 2735, 2507, 1681, 1851, 1502, 1427, 1368; ${ }^{1} \mathrm{H}-\mathrm{NMR}\left(400 \mathrm{MHz}\right.$, DMSO- $\left.d_{6}\right): \delta 14.38(\mathrm{~s}$, $1 \mathrm{H}, \mathrm{OH}), 10.15$ (bs, NH, NHEt 2 ), 7.64-7.23 (m, $12 \mathrm{H}, \mathrm{Ph}), 5.69(\mathrm{~s}, 1 \mathrm{H}$, benzyl-H), $3.23(\mathrm{~s}, 6 \mathrm{H}$, $\left.\mathrm{CH}_{3}\right), \quad 2.22\left(\mathrm{t}, 4 \mathrm{H}, J=7.3 \mathrm{~Hz}, \mathrm{CH}_{2} \mathrm{CH}_{3}\right), 1.97(\mathrm{~s}$, $\left.3 \mathrm{H}, \mathrm{CH}_{3}\right), 0.58\left(\mathrm{t}, 6 \mathrm{H}, J=7.3 \mathrm{~Hz}, \mathrm{CH}_{2} \mathrm{CH}_{3}\right) ;{ }^{13} \mathrm{C}-$ NMR $\left(100 \mathrm{MHz}, \mathrm{DMSO}-d_{6}\right): \delta=192.5,164.6$, $156.5,152.7,147.1,129.6,129.2,128.8,128.2$, 127.4, 125.7, 121.9102.9, 91.7, 41.2, 34.2, 28.3, 14.4, 12.8, 10.8, 10.10.6; Anal. for $\mathrm{C}_{31} \mathrm{H}_{35} \mathrm{~N}_{5} \mathrm{O}_{4}$; calcd $\mathrm{C}, 68.74 ; \mathrm{H}, 6.51 ; \mathrm{N}, 12.93$; Found: $\mathrm{C}$, 68.74; H, 6.50; N, 12.90; LC/MS (ESI):542 [M] ${ }^{+}$.

\section{5-((6-hydroxy-1,3-dimethyl-2,4-dioxo-1,2,3,4- tetrahydropyrimidin-5-yl)(thiophen-2- yl)methyl)-3-methyl-1-phenyl-1H-pyrazol-4- olate (40)}

40 was prepared according to (GP1) from thiophenldehyde yielding red materials (yield 85\%). m.p: $103{ }^{\circ} \mathrm{C}$; IR (Csl, $\mathrm{cm}^{-1}$ ): 3451, 3079, $2988,2740,2504,1682,1582,1500,1413$, 1336, 1304, 1210; ${ }^{1} \mathrm{H}-\mathrm{NMR}$ (400 MHz, DMSO- $d_{6}$ ): $\delta 14.30(\mathrm{~s}, 1 \mathrm{H}, \mathrm{OH}), 8.70$ (bs, NH, NHEt ${ }_{2}$ ), $7.98(\mathrm{~d}, 2 \mathrm{H}, J=7.3 \mathrm{~Hz}$, thiophene), $7.59(\mathrm{~d}, 1 \mathrm{H}, J$ $=7.3 \mathrm{~Hz}$, thiophene),7.98-7.07 (m, $6 \mathrm{H}, \mathrm{Ph}), 5.67$ (s, $1 \mathrm{H}$, benzyl-H), $3.16\left(\mathrm{~s}, 6 \mathrm{H}, \mathrm{CH}_{3}\right), 2.33(\mathrm{t}, 4 \mathrm{H}$, $\left.J=7.3 \mathrm{~Hz}, \mathrm{CH}_{2} \mathrm{CH}_{3}\right), 2.20\left(\mathrm{~s}, 3 \mathrm{H}, \mathrm{CH}_{3}\right), 0.77$ (t, $\left.6 \mathrm{H}, J=7.3 \mathrm{~Hz}, \mathrm{CH}_{2} \mathrm{CH}_{3}\right) ;{ }^{13} \mathrm{C}-\mathrm{NMR}(100 \mathrm{MHz}$, DMSO- $\left.d_{6}\right): \delta=192.8,162.3,156.4,150.2,146.6$, $140.9,138.7,138.4,138.3,136.8,136.5,128.9$, $128.8,124.9,121.9,119.1,104.1,91.4,41.5$, 30.6, 28.3, 13.1, 12.4, 10.8; Anal. for $\mathrm{C}_{25} \mathrm{H}_{31} \mathrm{~N}_{5} \mathrm{O}_{4} \mathrm{~S}$; calcd C, 60.34; $\mathrm{H}, 6.28 ; \mathrm{N}, 14.07$; S, 6.44.; Found: C, 60.34; H, 6.27; N, 14.10; S, 6.45; LC/MS (ESI): 498 [M] ${ }^{+}$.

The desired compounds 4a-o were synthesized in one step fashion in high yield. The chemical structure was assigned via different spectroscopic tools including NMR, IR, MS and $\mathrm{CHN}$ elemental analysis.

A possible mechanism for the tandem AldolMichael reaction is shown in scheme 2. In the first step of the reaction, olefin is produced by Aldol condensation between aryl aldehyde 1 and either $\mathbf{2}$ or $\mathbf{3}$ promoted by diethyl amine (DEA). The Michael addition occurred in the second step via addition of enolate into olefin to afford the final desired products 4 a-o.

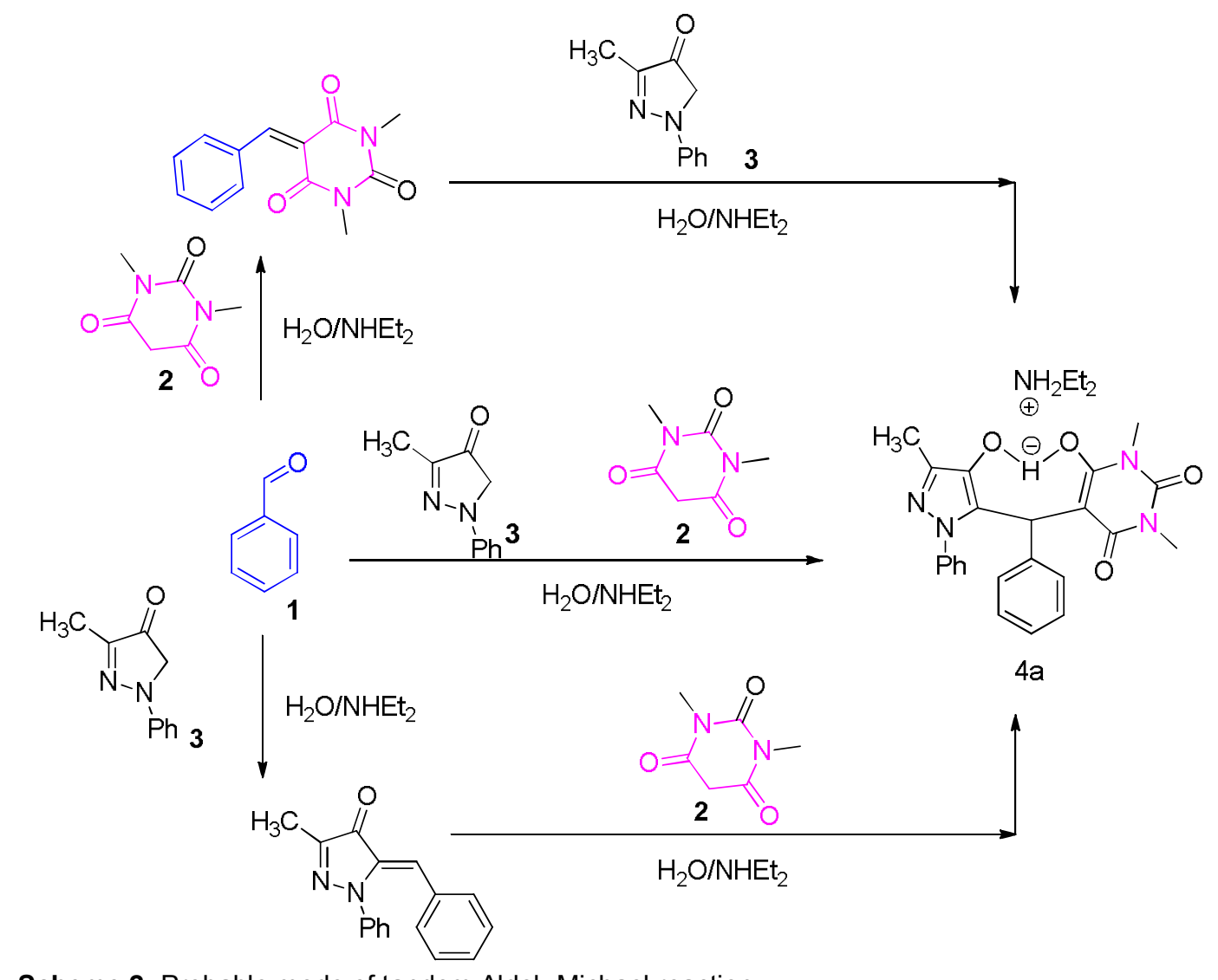

Scheme 2: Probable mode of tandem Aldol- Michael reaction 


\section{Antimicrobial activity}

Results of the biological activity are shown in Table 2 and are expressed in $\mathrm{mm}$ inhibition. All the compounds exhibited very good activity against Gram-positive bacteria and fungi. The most promising compound against $C$. albicans was $4 \mathrm{j}$. Compounds $4 \mathrm{a}-\mathrm{o}$ had no activity against Gram-negative bacteria including Escherichia coli ATCC 25922, Proteus vulagris ATCC 6380, and Pseudomonas aeruginosa ATCC 27857.

\section{DISCUSSION}

Visual inspection of the binding mode of these newly synthesized compounds were carried out to determine the promising anti-fungal and antibacterial (gram-positive) agents.

As shown for the in vitro observations, the docking results confirmed the anti-fungal and gram positive anti-bacterial activity of these compounds, especially $\mathbf{4 j}$ and $\mathbf{4 c}$, revealed good interactions against the two target proteins (Fig. 2). Although, compounds $4 \mathrm{~h}, \mathbf{4 i}, \mathbf{4 l}, \mathbf{4 n}$ and $\mathbf{4 o}$ have some sort of activity but they did not show good interactions against the target proteins (4HOF and 4URM) like compound $4 \mathbf{j}$ and $4 \mathrm{c}$. Moreover, molecular docking of $\mathbf{4 j}$ against $4 \mathrm{HOF}$ showed that three hydrogen bonds and one arene-cation interaction with the active site residues Thr58, Lys57 and Arg56 respectively of protein (Figure 2a), Alternatively, docking simulation with gyrase B (PDB ID: 4URM) revealed that the carbonyl oxygen of compound 4j was involved in hydrogen bonding with active site residues Ile86 and Gly85 (Fig. 2b). In case of compound 4c, good interactions were observed with the active site residues of target protein $4 \mathrm{HOF}$ (Figure 2c) and 4URM (Figure 2d). The orientation of the compound $\mathbf{4 j}$ and $\mathbf{4 c}$ in the active site of the target proteins are represented in Figure 3. Overall our docking results showed that all the synthesized compounds, particularly compounds $4 \mathrm{j}$ and $\mathbf{4 c}$ revealed significant hydrogen bonds and hydrophobic interactions with the important active site residues of $4 \mathrm{HOF}$ and $4 U R M$ and are the promising anti-fungal and anti-bacterial agents respectively.

\section{CONCLUSION}

In conclusion, a new series of Michael adducts combined pyrazol-barbituric acid pharmacophore are synthesized and characterized. The synthesized products were examined against antimicrobial activity and also the molecular docking was investigated.

Table 2: Antimicrobial activity and minimal inhibitory concentrations of the compounds that show antimicrobial activity

\begin{tabular}{|c|c|c|c|c|c|c|c|c|c|}
\hline \multirow{3}{*}{ Tube no. } & \multirow{3}{*}{$\begin{array}{c}\text { Compound } \\
\text { no. }\end{array}$} & \multicolumn{6}{|c|}{ Gram positive bacteria } & \multirow{2}{*}{\multicolumn{2}{|c|}{$\begin{array}{c}\text { Yeast } \\
\text { C. albicans } \\
\text { ATCC } 2091\end{array}$}} \\
\hline & & \multicolumn{2}{|c|}{$\begin{array}{c}\text { S. aureus ATCC } \\
29213\end{array}$} & \multicolumn{2}{|c|}{$\begin{array}{c}\text { E. faecalis } \\
\text { ATCC29212 }\end{array}$} & \multicolumn{2}{|c|}{$\begin{array}{c}\text { B. subtilis } \\
\text { ATCC10400 }\end{array}$} & & \\
\hline & & $\begin{array}{l}C P M \\
(\mathrm{~mm})\end{array}$ & $\begin{array}{c}M I C \\
(m g / L)\end{array}$ & $\begin{array}{c}\mathrm{CPM} \\
(\mathrm{mm})\end{array}$ & $\begin{array}{c}\text { MIC } \\
(m g / L)\end{array}$ & $\begin{array}{l}C P M \\
(\mathrm{~mm})\end{array}$ & $\begin{array}{c}M I C \\
(m g / L)\end{array}$ & $\begin{array}{l}\mathrm{CPM} \\
(\mathrm{mm})\end{array}$ & $\begin{array}{c}M I C \\
(m g / L)\end{array}$ \\
\hline 1 & $4 a$ & 12 & 32 & 12 & 16 & 11 & 32 & 14 & 32 \\
\hline 2 & $4 b$ & 12 & 32 & 14 & 32 & 11 & 32 & 14 & 32 \\
\hline 3 & $4 c$ & 13 & 32 & 13 & 32 & 12 & 32 & 18 & 8 \\
\hline 4 & $4 d$ & 14 & 32 & 15 & 16 & 14 & 16 & 14 & 32 \\
\hline 5 & $4 e$ & 15 & 32 & 12 & 64 & 11 & 64 & 14 & 32 \\
\hline 6 & $4 f$ & 14 & 32 & 13 & 32 & 13 & 32 & 15 & 16 \\
\hline 7 & $4 g$ & 14 & 32 & 14 & 32 & 13 & 32 & 15 & 16 \\
\hline 8 & $4 h$ & 15 & 32 & 15 & 32 & 14 & 32 & 12 & 128 \\
\hline 9 & $4 i$ & 15 & 32 & 19 & 32 & 15 & 16 & 13 & 64 \\
\hline 10 & $4 j$ & 14 & 32 & 14 & 16 & 15 & 32 & 17 & 8 \\
\hline 11 & $4 k$ & 12 & 32 & 12 & 32 & 11 & 32 & 16 & 16 \\
\hline 12 & $4 I$ & 10 & $>128$ & Nil & $>128$ & 13 & 32 & 10 & $>128$ \\
\hline 13 & $4 m$ & 12 & 32 & 12 & 32 & 14 & 16 & 16 & 16 \\
\hline 14 & $4 n$ & 13 & 64 & 11 & 64 & 12 & 64 & 14 & 32 \\
\hline 15 & 40 & 13 & 64 & 11 & 64 & 14 & 16 & 15 & 16 \\
\hline \multirow[t]{2}{*}{ Standard } & Ciprofloxacin & 27 & $\leq 0.25$ & 24 & $\leq 0.25$ & 25 & $\leq 0.25$ & ND & ND \\
\hline & Fluconazole & ND & ND & ND & ND & ND & ND & 28 & 0.5 \\
\hline
\end{tabular}



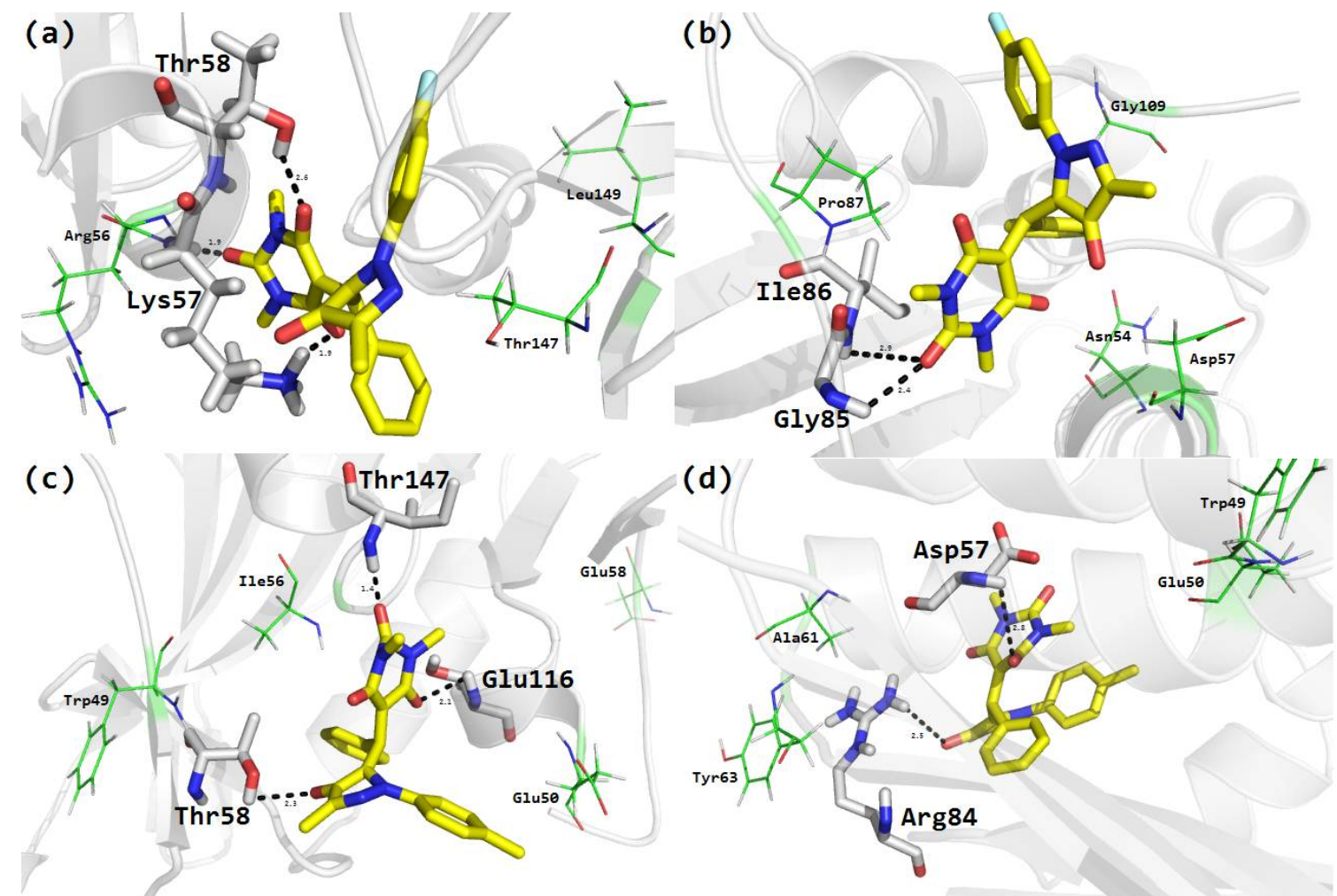

Figure 2: (a) Molecular docking conformation of compound $4 \mathbf{j}$ in the active site of $4 \mathrm{HOF}$; (b) Molecular docking conformation of compound $\mathbf{4} \mathbf{j}$ in the active site of $4 \mathrm{URM}$; (c) Molecular docking conformation of compound $\mathbf{4 c}$ in the active site of $4 \mathrm{HOF}$; (d) Molecular docking conformation of compound $4 \mathrm{c}$ in the active site of $4 \mathrm{URM}$

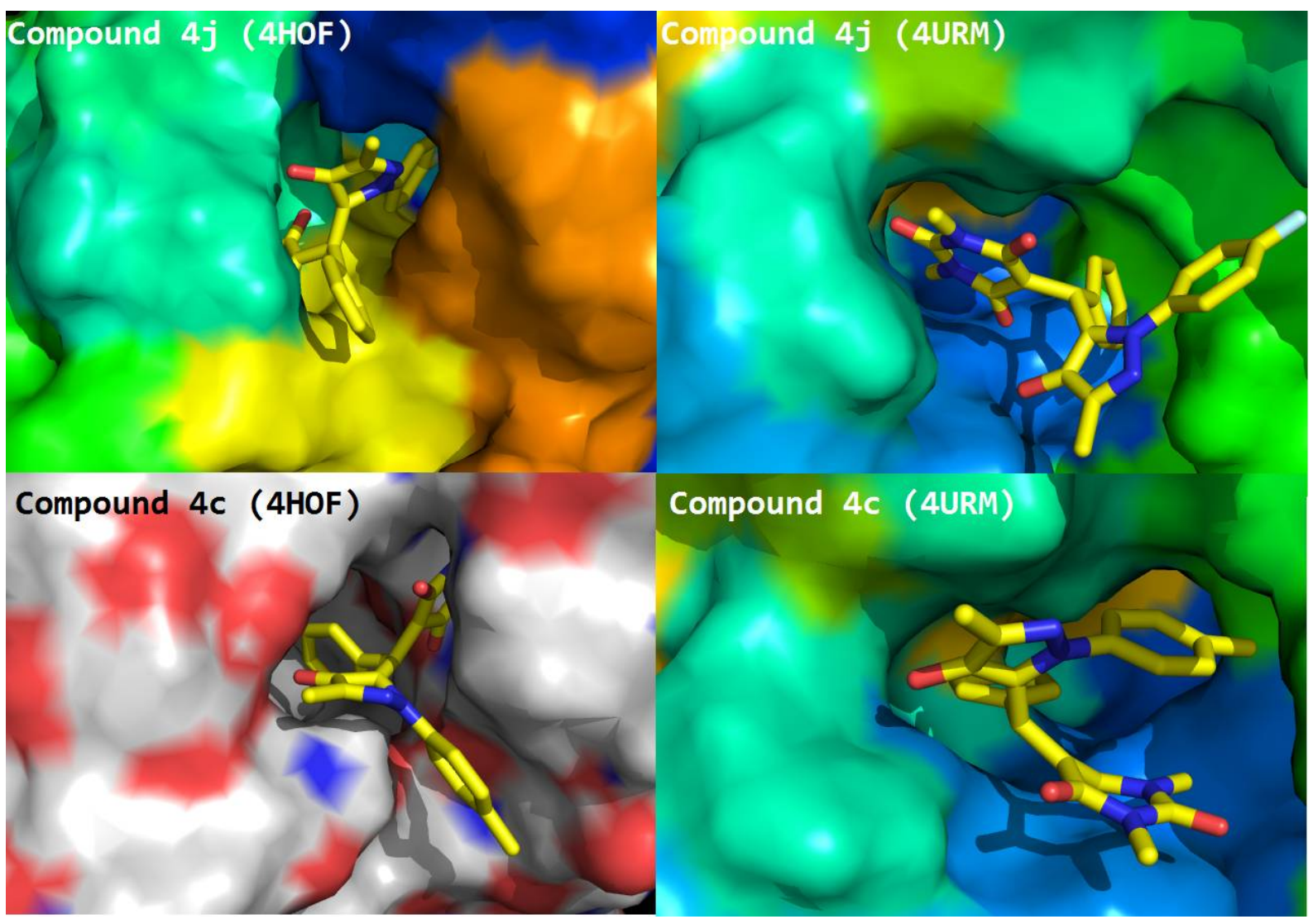

Figure 3: Binding orientation of compound $\mathbf{4 j}$ and $\mathbf{4 c}$ in the active sites of $4 \mathrm{HOF}$ and 4URM 


\section{DECLARATIONS}

\section{Acknowledgement}

The authors would like to extend their sincere appreciation to Deanship of Scientific Research at King Saud University for funding Research Group no. RG -257-1435-1436.

\section{Conflict of Interest}

No conflict of interest associated with this work.

\section{Contribution of Authors}

The authors declare that this work was done by the authors named in this article and all liabilities pertaining to claims relating to the content of this article will be borne by them.

\section{REFERENCES}

1. Padwa A. Domino reactions of rhodium(II) carbenoids for alkaloid synthesis. Chem Soc Rev 2009; 38: 3072-3081.

2. Tietze LF, Aunert, F, Votle F. Stimulating Concepts in Chemistry. Wiley-VCH: Weinheim, 2000; pp 39-64.

3. Shore G, Yoo WJ, Li CJ, Organ MG. Invited Inside Front Cover Article: Propargyl Amine Synthesis Catalysed by Gold and Copper Thin Films Using Microwave-Assisted, Continuous Flow Organic Synthesis (MACOS). Chem Eur J 2010; 16: 126-133.

4. Armstrong RW, Combs AP, Tempest PA, Brown SD, Keating TA. Multiple-Component condensation strategies for combinatorial library synthesis. Acc Chem Res 1996; 29: 123-131.

5. Dax SL, McNally JJ, Yougman MA. Multi-component methodologies in solid-phase organic synthesis. Curr Med Chem 1999; 6: 255-270.

6. Lindstrom UM. Organic Reactions in Water: Principles, Strategies and Applications; Wiley-Blackwell, Oxford, UK, 2007.

7. Narayan S, Muldoon J, Finn MG, Fokin VV, Kolb HC, Sharpless KB. "On Water": Unique Reactivity of Organic Compounds in Aqueous Suspension. Angew Chem Int Ed 2005; 44: 3275-3279.

8. Abunada NM, Hassaneen HH, Kandile NG, Miqdad OA. Synthesis and antimicrobial activity of some new pyrazole, fused pyrazolo[3,4-d]-pyrimidine and pyrazolo[4,3-e][1,2,4]- triazolo[1,5-c]pyrimidine derivatives. Molecules 2008; 13: 1501-1517.

9. Lamberth C. Pyrazole chemistry in crop protection. Heterocycles 2007; 71:1467-1502.

10. Dressen D, Garofalo AW, Hawkinson J, Hom D, Jagodzinski J, Marugg JL, Neitzel ML, Pleiss MA, Szoke $B$, Tung JS, Wone DW. Preparation and optimization of a series of 3-carboxamido-5-phenacylaminopyrazole bradykinin B1 receptor antagonists. J Med Chem 2007; 50: 5161-5167.
11. Chavatte P, Yous S, Marot C, Baurin N, Lesieur D. Three-dimensional quantitative structure-activity relationships of cyclo-oxygenase-2 (COX-2) inhibitors: A comparative molecular field analysis. I Med Chem 2001; 44: 3223-3230.

12. Woessner KM, Simon RA, Stevenson $D D$. The safety of celecoxib in patients with aspirin-sensitive asthma. Arthritis Rheum 2002; 46: 2201-2206.

13. Fong TM, Heymsfield SB. Cannabinoid-1 receptor inverse agonists: current understanding of mechanism of action and unanswered questions. Int J Obes 2009; 33: 947-955.

14. Gudmundsson KS, Johns BA, Allen $S H$. Pyrazolopyridines with potent activity against herpesviruses: Effects of C5 substituents on antiviral activity. Bioorg Med Chem Lett 2008; 18: 1157-1161.

15. Kendre $D B$, Toche RB, Jachak MN. Synthesis of novel Dipyrazolo [3, 4-b: 3, 4-d] pyridines and study of their fluorescence behavior. Tetrahedron 2007; 63:1100011004.

16. Bazgira A, Khanaposhtani MM, Soorki AA. One-pot synthesis and antibacterial activities of pyrazolo [4', 3': 5, 6] pyrido [2, 3-d] pyrimidine-dione derivatives. Bioorg Med Chem Lett 2008; 18: 5800-5803.

17. Varma RS. Solvent-free organic syntheses. Using supported reagents and microwave irradiation. Green Chem 1999; 1: 43-55.

18. Trost BM, Brennan MK. Asymmetric syntheses of oxindole and indole spirocyclic alkaloid natural products. Synthesis 2009; 18: 3003-2025.

19. Ranjith, Kumar $R$, Perumal $S$, Senthilkumar $P$, Yogeeswari $P$, Sriram DA. facile synthesis and antimycobacterial evaluation of novel spiro-pyridopyrrolizines and pyrrolidines. Eur J Med Chem 2009; 44: 3821-3829.

20. Wu YS, Cai J, Hu ZY, Lin GH. A new class of metal-free catalysts for direct diastereo-and regioselective Mannich reactions in aqueous media. Tetrahedron Lett 2004; 45 : 8949-8952.

21. Barakat A, Al-Majid AM, Al-Najjar HJ, Mabkhot YN, Javaid S, Yousuf S, Choudhary MI. Zwitterionic pyrimidinium adducts as antioxidants with therapeutic potential as nitric oxide scavenger. Euro J Med Chem 2014; 84: 146-154.

22. Al-Majid AM, Barakat A, Al-Najjar HJ, Mabkhot YN, Ghabbour HA, Fun HK. Tandem Aldol-Michael reactions in aqueous diethylamine medium: a greener and efficient approach to bis-pyrimidine derivatives. Inter $J$ Mol Sci 2013; 14(12): 23762-23773.

23. Barakat A, Al-Majid AM, Shahidul MI, Warad I, Masand $\mathrm{VH}$, Yousuf S, Choudhary MI. Molecular structure investigation and biological evaluation of Michael adducts derived from dimedone. Research on Chemical Intermediates 2016; 42(5): 4041-4053.

24. BSAC. Methods for Antimicrobial Susceptibility TestingVersion 14 Available at: http://bsac.org.uk/wpcontent/uploads/2012/02/BSAC-Susceptibility-testingversion-14.pdf (Last accessed 9 April 2015).

Trop J Pharm Res, October 2016; 15(10): 2206 
Barakat et al

25. Molecular Operating Environment (MOE, 2013). Canada.

Chemical Computing Group Inc.: Montreal, QC, 